\title{
The Study of Antibacterial Activity of Benzimidazole Derivative Synthesized from Citronellal
}

\author{
Uthumporn Kankeaw*, Ratchaneeporn Rawanna \\ Department of Chemistry, Faculty of Science, Maejo University, Chiang Mai, 50290, Thailand \\ * Corresponding author. Tel.: 66892013646; email: mooeed@hotmail.com \\ Manuscript submitted April 13, 2015; accepted June 22, 2015. \\ doi: 10.1776/ijbbb.2015.5.5.280-287
}

\begin{abstract}
Benzimidazole is an adsorption reagent and popularly used in production of anthelmintic, antifungal and antibacterial drugs. Benzimidazole is chemical reagent including of heterocyclic aromatic. In this work, citronellal was used as the starting material which was extracted from Citrus hystrix (makrut lime) leaves that contains aldehyde functional group. The essential oil was reacted with 1,2-phenylene diamine via condensation reaction in ethanol to give benzimidazole derivative. The synthesized derivatives are characterized by fourier transform infrared spectroscopy (FT-IR) that exhibited the spectrum (N-H str) at $3389 \mathrm{~cm}^{-1}$, (C-N str) $1272 \mathrm{~cm}^{-1}$, (C=C str) of benzene ring at 1655 and $1460 \mathrm{~cm}^{-1}$ and (C=C str) of alkene at $1379 \mathrm{~cm}^{-1}$ respectively which are a functional group of benzimidazole. Moreover, when compared between the IR spectrum of product compound and the substrate (citronellal), it was found that the character peak of aldehyde $(\mathrm{C}=0)$ was missed due with the reaction. In addition to these product was tested the antibacterial activity with Gram negative, Escherichia coli (E. coli), and Gram positive, Staphylococcus Aureus , bacterial strains by disc-diffusion methods at a concentration of $200 \mathrm{mg} / \mathrm{ml}$, using ethanol as the control, compare with antibacterial drug, Gentamicin. These result suggest that the derivative effective excellent antibacterial against than antibacterial drug. It may be the medicine to prevent and treat many bacterial diseases.
\end{abstract}

Key words: Benzimidazole, citronellal, lime leaves.

\section{Introduction}

Benzimidazoles were reported to have antimicrobial properties [1] against bacteria or fungi. The azetidinone ring bearing compounds showed varied biological activities like antibacterial and antifungal activities. The wide range of therapeutic value of these nuclei promoted the synthesis of compounds comprised of the benzimidazole derivatives with substitution at 2 position with essential oil from Citrus hystrix (makrut lime) leaves would possess potential antimicrobial properties. Essential oils extracted from plants may have antibacterial properties with synergistic interactions among them [2]. Essential oils usually consist of a large number of components and it is likely that their mode of action involves many targets in bacterial cells. A number of essential oil components have been identified as antibacterials such as carvacrol [2], citral, eugenol, geraniol, perillaldehyde, and thymol. In addition, essential oils have antioxidant, repellent, insecticidal [3], antifungal [4], antiviral [5], and antiparasitic activities[6]. Makrut lime oil was reported to be effective against 20 serotypes of Salmonella and 5 species of other enterobacteria.

Essential oils and extracts from a wide variety of plants have long been used for medicinal purposes [2]. 
They are potential sources of novel drugs especially against bacterial pathogens. Citrus hystrix DC, commonly known as makrut lime, is a common tropical herb in the family Rutaceae found everywhere in Southeast Asia [7]. Makrut lime is a thorny bush with aromatic leaves and dark green fruits with irregular bumpy surface. The valued parts of makrut lime are the leaves and fruit peel. Makrut lime is a key ingredient in many Thai, Cambodian, Indonesian, Laotian, Malaysian, and Philippine cuisines. The essential oils have been used as flavour and fragrance agents, as well as in perfumery and medicinal preparation. Essential oils usually consist of a large number of components and it is likely that their mode of action involves many targets in bacterial cells. A number of essential oil components have been identified as antibacterials such as carvacrol citral, eugenol, geraniol, perillaldehyde and thymol [8]-[13]. Makrut lime oil was reported to be effective against 20 serotypes of Salmonella and 5 species of other enterobacteria[14].

It is well known that essential oils from Citrus spp. have pronounced antimicrobial effect against both bacteria and fungi. [15]-[17] Citrus essential oils could represent good candidates to improve the shelf life and the safety of minimally processed fruits skim milk and low-fat milk. However, most studies have focused on essential oils from subtropical citrus. The essential oils from two cultivars of tropical citrus, including Citrus hystrix DC., and Citrus aurantifolia exhibited antimicrobial activity against Bacillus cereus, Staphylococcus aureus and Salmonella typhi [18].

From the previous study [19], a series of 1,2-substituted benzimidazole derivatives were synthesized without Schiff base or 2-substituted benzimidazole compounds as by product in order to investigate their antifungal activities. Its derivatives were characterized by IR and ${ }^{1} \mathrm{H}-\mathrm{NMR}$ spectroscopy. The compounds were screened for antifungal activity against Fusarium spp., which causes fungal diseases in tomatoes. The minimum inhibitory concentrations were determined by poison food and soaking techniques. The Seven aldehydes including thiophene-2-carboxaldehyde, 2-bromo-benzaldehyde, benzaldehyde, tert-butylbenzaldehyde, 3-nitro benzaldehyde, fural-2-carboxaldehyde and pyridine-2-carboxaldehyde were used as starting materials. After refluxing with 1,2-phenylenediamine in ethanol, only thiophene-2-carboxaldehyde and 3-nitrobenzaldehyde afforded 1,2-substituted benzimidazole compounds without Schiff base or 2-substituted benzimidazole compounds as by products. The products were tested for anti-fungal, Fusarium spp., which causes fungal diseases in tomatoes. The minimum inhibitory concentrations were determined by poison food technique and soaking techniques. Only 3-nitrobenzimidazole was found to exhibit the most potent anti-fungal activity by poison food technique (1000 ppm) and by soaking technique (125 ppm).

In the present study, the derivative benzimidazole were synthesized by the condensation between 1,2phenylene diamine and citronellal (Fig. 1) afford the product without Schiff base compound as by product in order to improve antibacterial activities.

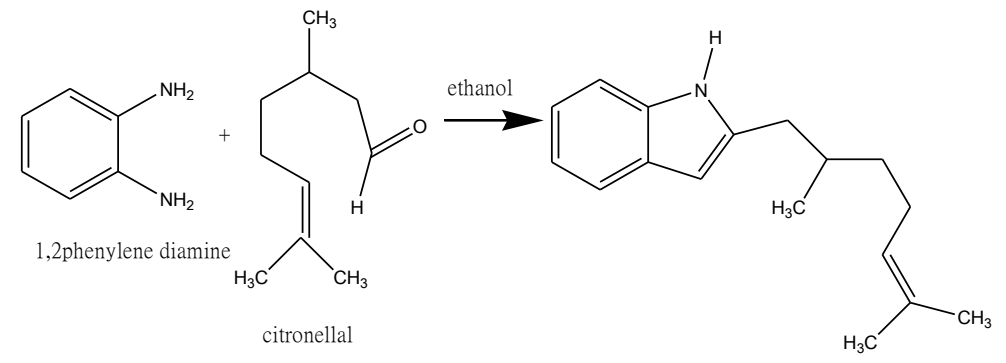

Fig. 1. Synthesis of benzimidazole from 1,2-phenylinediamine and citronellal.

\section{Materials and Methods}

\subsection{Materials}

The makrut leaf oil was obtained from Tropical market in Chiang Mai. The products were prepared by 
steam distillation. [20]

IR spectra of the compounds were recorded on Perkin Elmer FTIR spectrometer with $\mathrm{KBr}$ pellets. ${ }^{1} \mathrm{H}-\mathrm{NMR}$ spectra were recorded on $400 \mathrm{MHz}$ - Bruker AMX AVANCE. The chemical shifts were reported as parts per million down field from tetramethylsilane.

All the compounds gave satisfactory chemical analyses $( \pm 0.4 \%)$. The purity of the compounds was checked by TLC on precoated $\mathrm{SiO}_{2}$ gel (HF254 200 mesh) aluminum plates (E Merck).

\subsection{The Essential Oil Extraction}

The volatile oils of the makrut leaf oil were obtain by hydrodistillation [20]. $1 \mathrm{~kg}$ of each of makrut leaf powders with $3 \mathrm{~L}$ of distilled water followed by heating at $100{ }^{\circ} \mathrm{C}$ for $8 \mathrm{~h}$. The volatile products were extracted from the water phase three times using methylene dichloride. The essential oil was characterized the structure by FT-IR spectroscopy.

\subsection{The Synthesis of Benzimidazole Derivative}

The synthetic strategy leading to the target compounds is illustrated in Fig. 1. The benzimidazole derivative was synthesized by mixing 0.05 mole of 1,2-phenylenediamine and 0.10 mole of citronelal in 30 $\mathrm{mL}$ ethanol and refluxed for 2-6 hr. The mixture was cooled for $1 \mathrm{~d}$ and filtered. The product was recrystallized with absolute alcohol [21].

\subsection{Antibacterial Activity}

The antibacterial activity of the essential oils was tested by disc-diffusion method. [22] A sterile Whatman disc $(6 \mathrm{~mm})$ saturated with benzimidazole in the concentration of $200 \mathrm{mg} / \mathrm{ml}$ in ethanol was put on a lawn of a bacterial inoculum (Escherichia coli (E. coli) and Staphylococcus Aureus) which has a turbidity in $1 \%(\mathrm{w} / \mathrm{v})$ tryptone water equated to a Mc-Farland No 0.5 standard (approximately $108 \mathrm{CFU} / \mathrm{ml}$ ). All values of inhibition zones were expressed as mean \pm standard deviation. For broth microdilution method, the broth was supplemented with $0.25 \%$ (v/v) tween-20 (Sigma Chemical Co.,USA).

\section{Results and Dicussion}

\subsection{The Essential Oil Extraction}

The volatile oils of makrut leaf oil were obtain by hydrodistillation give the liquid yellow with unique aromatic scent the result and percent yield was shown in Table 1.

Table 1. The Quality of the Volatile Oil of Makrut Leaf Oil by Hydrodistillation

\begin{tabular}{|c|c|c|c|}
\hline & $\begin{array}{l}\text { Weight of bark } \\
\text { (kg) }\end{array}$ & $\begin{array}{c}\text { Weight of } \\
\text { volatile oil (g) }\end{array}$ & $\%$ yield \\
\hline 1 & 1.03 & 2.65 & 0.26 \\
\hline 2 & 1.09 & 2.27 & 0.21 \\
\hline 3 & 1.07 & 2.66 & 0.25 \\
\hline average & 1.06 & 2.53 & 0.24 \\
\hline
\end{tabular}

The volatile oil was characteristic by IR spectroscopy compare with reference spectrum [23] is presence in Fig. 2. It was found that the volatile oil is citronellal because there are the present peak of $1726 \mathrm{~cm}^{-1}(\mathrm{C}=0$ stretching), 2925, $2857 \mathrm{~cm}^{-1}$ (C-H stretching of aldehyde) and 1447, $1378 \mathrm{~cm}^{-1}$ (C=C stretching of aromatic), respectively. When compare the spectrum with the reference [24] found that there's dissimilar.

\subsection{The Synthesis of Benzimidazole Derivative}

The benzimidazole derivative was done by the condensation between 1,2-phenylene diamine and citronellal, the result show in Table 2. 
Table 2. The Synthesis of Benzimidazole

\begin{tabular}{llcc}
\hline \hline & $\mathrm{R}_{\mathrm{f}}^{*}$ & \%yield & melting point $\left({ }^{\circ} \mathrm{C}\right)$ \\
\hline $\begin{array}{l}\text { 2-(citronellyl) } \\
\text { benzimidazole }\end{array}$ & 0.64 & 92.8 & $178.0-177.5$ \\
& & & \\
\hline
\end{tabular}

* hexane: ethyl acetate: methanol $(5: 4: 1)$
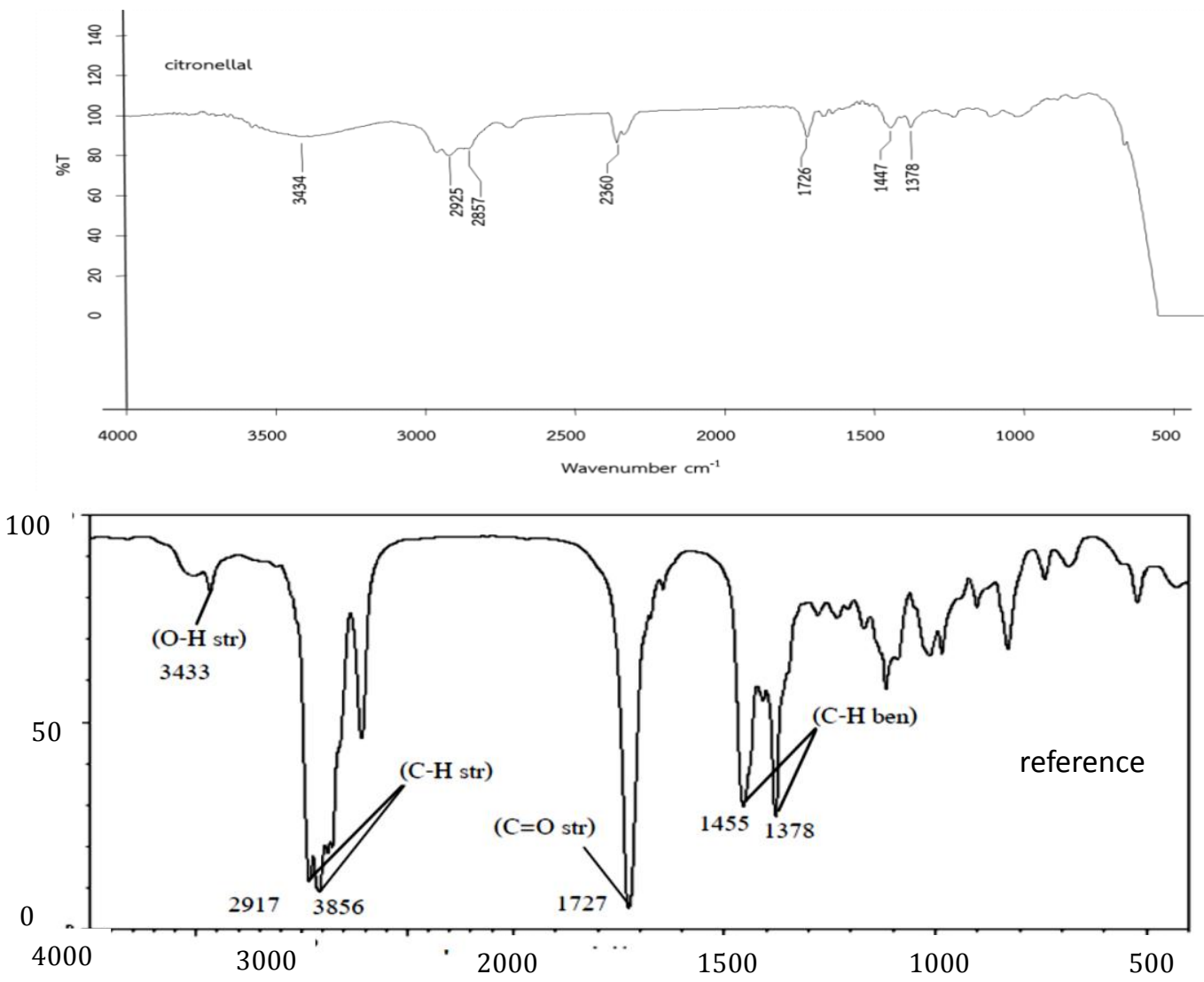

Fig. 2. The FT- IR spectrum of volatile oil.

The benzimidazole derivative was purified by recrystallization with ethanol. The mechanism of the reaction can be express in Fig. 3 that the lone pair electron of amino group perform as nucleophile attack to carbonyl group of citonellal afford the benzimidazole derivative.

Table 3. The Spectral Data

\begin{tabular}{|c|c|c|}
\hline Type of Experiment & Unit & Data \\
\hline $\begin{array}{l}\text { IR Perkin Elmer } \\
\text { FTIR }\left(450-4000 \mathrm{~cm}^{-1}\right)\end{array}$ & $\mathrm{cm}^{-1}$ & $\begin{array}{l}3383(\mathrm{~N}-\mathrm{H} \text { bond }), 1381(\mathrm{C}=\mathrm{C} \text { of alkene }), 1448,1640(\mathrm{C}=\mathrm{C} \text { of } \\
\text { aromatic), } 2979(\mathrm{C}-\mathrm{H} \text { stretch }), 1048,1088\left(\mathrm{CH}_{3}, \mathrm{CH}_{2} \mathrm{gp}\right), 880 \text {, } \\
667(\mathrm{C}=\mathrm{C} \text { of aromatic })\end{array}$ \\
\hline $\begin{array}{l}{ }^{1} \mathrm{H}-\mathrm{NMR} \text { Bruker } \\
(400 \mathrm{MHZ})\end{array}$ & $\delta \mathrm{ppm}$ & $\begin{array}{l}3.47(\mathrm{~s}, 1 \mathrm{H}, \mathrm{NH}), 7.21,7.48(\mathrm{~d}, 4 \mathrm{H} \text {, aromatic protons }) \text { and } 5.03(\mathrm{t}, \\
1 \mathrm{H},-\mathrm{CH}=),\end{array}$ \\
\hline
\end{tabular}

The synthesis product was characterized by FT-IR spectroscopy which showed single spectrum at 3383 $\mathrm{cm}^{-1}$, this indicates the present of $(\mathrm{N}-\mathrm{H})$ stretch for secondary of amine group. The frequency at $1381 \mathrm{~cm}^{-1}$ 
is due to $(\mathrm{C}=\mathrm{C})$ stretch for alkene. Moreover the double peak, $16401448 \mathrm{~cm}^{-1}$ show the characteristic of $(\mathrm{C}=\mathrm{C})$ stretch for aromatic, respectively. The characterization by ${ }^{1} \mathrm{H}-\mathrm{NMR}$ spectroscopy expressed ${ }^{1} \mathrm{H}-\mathrm{NMR}$ (ppm): 3.47 (s, 1H, NH), 7.21, $7.48(\mathrm{~d}, 4 \mathrm{H}$, aromatic protons) and $5.03(\mathrm{t}, 1 \mathrm{H},-\mathrm{CH}=)$, respectively (Table 3) . From the FT-IR spectrum, it was found that $\mathrm{C}-\mathrm{H}$ stretching of aldehyde was disappearing in the other hand, $\mathrm{NH}$ stretching which is the character of benzimidazole was appeared. It can be concluded that the modified structure was followed by expect reaction.
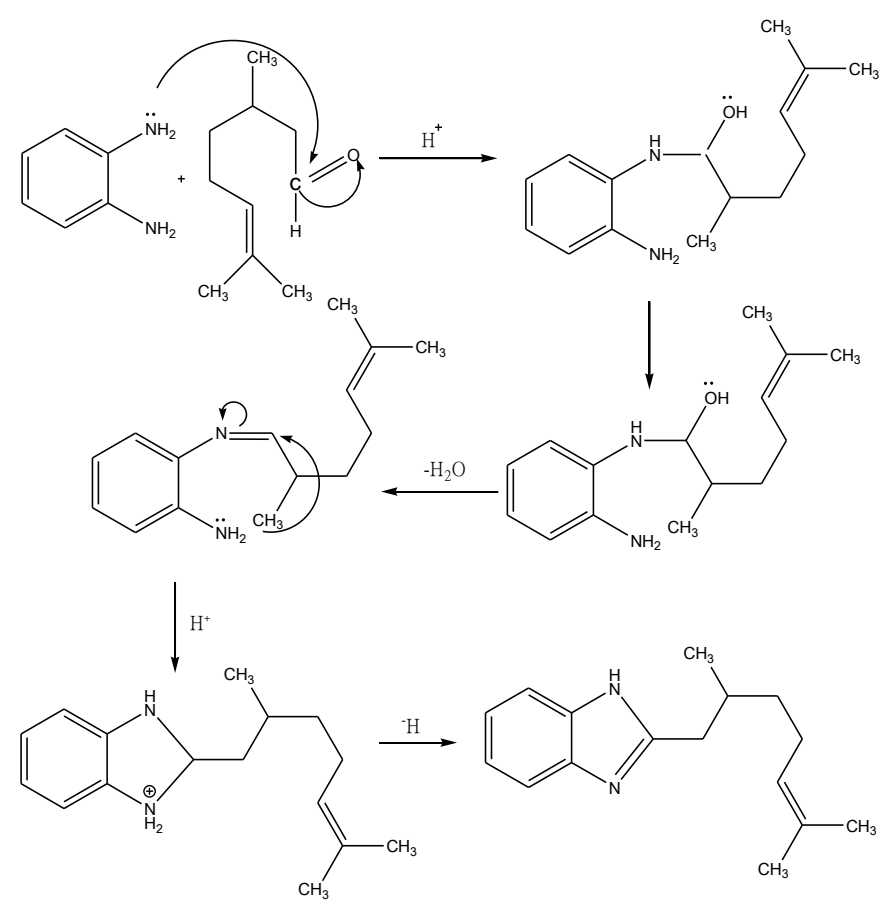

Fig. 3. The mechanism of the synthesis of benzimidazole.

\subsection{Antibacterial Activity}

The Result of the zone of inhibition of benzimidazole derivative against selected micro-organism was given in Fig. 4 and Table 4.

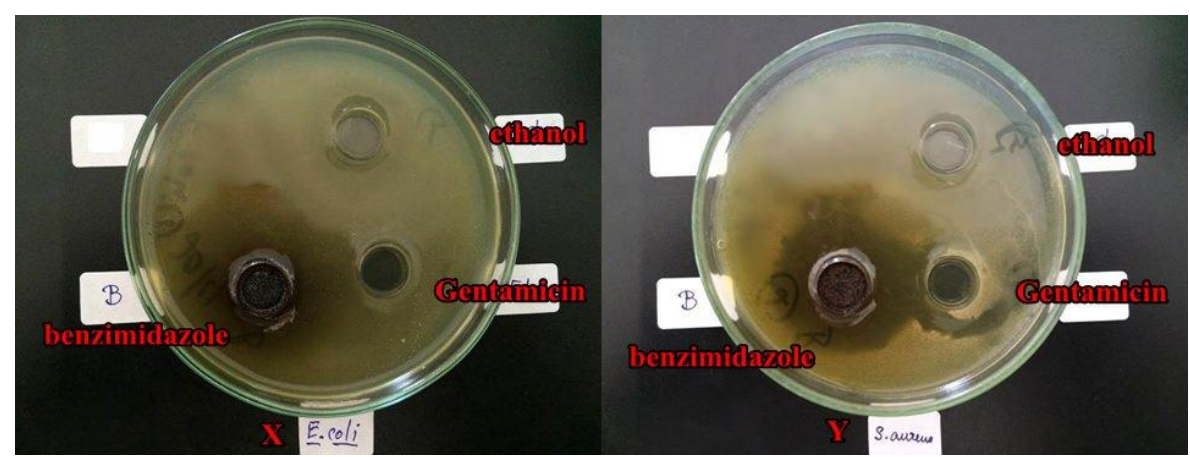

Fig. 4. Anti-bacterial ACTIVITY. X= Escherichia coli, $\mathrm{Y}=$ Staphylococcus Aureus

The antibacterial activity of bezimidazole derivative is mainly due to the active of azetidinone ring and the functional group in their structure. In this study, the derivative was compare with Gentamicin which is the antibacterial drug by disc-diffusion methods. The diameter of inhibition zones was measured in $\mathrm{mm}$ and the results were recorded inhibition zones with diameter less than $12 \mathrm{~mm}$ were considered as having no antibacterial activity. Diameters between 12 and 16mm were considered 
moderately active and these with $\geq 16 \mathrm{~mm}$ were considered highly active [25]. It was found that the antibacterial of benzimidazole product express the excellent activity in gram positive bacteria with the inhibizone area around $19 \mathrm{~mm}$ and give the moderate result in gram negative bacterial with the inhibizone area around $15 \mathrm{~mm}$. As the result, when compare with Gentamicin which is the antibiotic amino glycoside drug, the benzimidazole give more excellent antibacterial than the drug. The antibacterial activity of citronelal were reported by Kotan et al. [26], it express that the oil cannot be anti E.coli and give very low activity with Staphylococcus Aureus. It was evident that the present study results were confirmed the modifcation of the structure of citronelal can improve the antibacterial inhibition against.

Table 4. The Antibacterial Activity of Benzimidazole Derivative

\begin{tabular}{lllc}
\hline \hline Pathogens & $\begin{array}{l}\text { Gentamicin } \\
\mathrm{mm}\end{array}$ & $\begin{array}{l}\text { Ethanol } \\
\mathrm{mm}\end{array}$ & $\begin{array}{c}\text { benzimidazole derivative } \\
\mathrm{mm}\end{array}$ \\
\hline Escherichia coli (E. coli) & 9 & 9 & 15.3 \\
Staphylococcus Aureus & 9.3 & 9 & 19.5 \\
\hline \hline
\end{tabular}

\section{Conclusion}

This present study has revealed that the antibacterial activity of benzimidazole derivative which was synthesis by the condensation between 1,2-phenylene diamine and citronellal. This study showed the potent antibacterial and may be efficient as preventive agents in and can be seen as a potential source of useful drugs. Further studies have to be carried out to modification of the structure for higher activity was done by 1,2-substitued on azetidinone ring.

\section{Acknowledgment}

We are thankful to The Department of Chemistry, Faculty of Science, Maejo University for financial support and providing all necessary facilities to conduct the experiments.

\section{References}

[1] David, W., Zhijan, K., \& Christine, C. (2004). Synthesis of dicationic extended bis-benzimidazoles. Molecules, 9, 158-163.

[2] Vimol, S., Chanwit, T., Veena, N., Nuntavan, B., Kulkanya, C., Siwimol, P., et al. (2012). Antibacterial activity of essential oils from Citrus hystrix (makrut lime) against respiratory tract pathogens. Science Asia, 38, 212-217.

[3] Burt, S. J. (2004). Essential oils: Their antibacterial properties and potential applications in food-a review. International Journal of Food Microbiology, 94, 223-253.

[4] Fontenelle, R. O., Morais, S. M., Brito, E. H., Brilhante, R. S., Cordeiro, R. A., Nascimento, N. R., Kerntopf, M. R., Sidrim, J. J., et al. (2008). Antifungal activity of essential oils of Croton species from the Brazilian Caatinga biome. Journal of Applied Microbiology, 104, 1383-1390.

[5] Khan, M. T., Ather, A., Thompson, K. D., \& Gambari, R. (2005). Extracts and molecules from medicinal plants against herpes simplex viruses. Antivirus Research, 67, 107-119.

[6] Pessoa, L. M., Morais, S. M., Bevilaqua, C. M. L., \& Luciano, J. H. S. (2002). Antihelminthic activity of essential oil of Ocimum gratissimum Linn. and eugenol against Haemonchus contortus. Journal of Applied Microbiology, 109, 59-63.

[7] Doreen, S. H., Rose, L. C., Suhaimi, H., Mohamad, H., Rozaini, M. Z. H., \& Tai, M. (2011). Preliminary 
evaluation onthe antibacterial activities of Citrus hystrix oil emulsionsstabilized by tween 80 and span 80. International Journal of Pharmacy and Pharmaceutical Sciences, 3(Suppl 2), 209-211.

[8] Burt, S. (2004). Essential oils: Their antibacterial properties and potential applications in food - a review. International Journal of Food Microbiology, 94, 223-253.

[9] Kim, J., Marshall, M. R., \& Wei, C. I. (1995). Antibacterial activity of some essential oil components against five foodborne pathogens. Journal of Agricultural and Food Chemistry, 43, 2839-2845

[10] Lambert, R. J., Skandamis, P. N., Coote, P. J., \& Nychas, G. J. (2001). A study of the minimum inhibitory concentration and mode of action of oregano essential oil, thymol and carvacrol. Journal of Applied Microbiology, 91, 453-462.

[11] Prabuseenivasan, S., Jayakumar, M., \& Ignacimuthu, S. (2006). In vitro antibacterial activity of some plant essential oils. BMC Compl Alternative Med, 6, 39-47.

[12] Sabulal, B., Dan, M., Pradeep, N. S., Valsamma, R. K., \& George, V. (2006). Composition and antimicrobial activity of essential oil from Amomum cannicarpum. Acta Pharmaceutica, 56, 473-480.

[13] Murugulla, A., \& Donthabhakthuni, S. (2011). Room temperature synthesis of benzimidazole derivatives using reusable cobalt hydroxide (II) and cobalt oxide (II) as efficient solid catalysts. Tetrahedral Letter, 52, 5575-5580.

[14] Nanasombat, S., \& Lohasupthawee, P. (2005). Antibacterial activity of crude ethanolic extracts and essential oils of spices against salmonellae and other enterobacteria. KMITL Science and Technology, 5, 527-538.

[15] Lanciotti, R., Gianotti, A., Patrignani, F., Belletti, N., Guerzoni, E. M., \& Gardini F. (2004). Use of natural aroma compounds to improve shelf-life and safety of mini-mally processed fruits. Trends Food Science and Technology, 15, 201-208.

[16] Dabbah, R., Edwards, M. V., \& Moats, A. W. (1970). Anti-microbial action of some citrus fruit oils on selected food borne bacteria. Journal of Applied Microbiology, 19, 27-31.

[17] Caccioni, D. R. L., Guizzardi, M., Biondi, D. M., Renda, A., \& Ruberto, G. (1998). Relationship between volatile components of citrus fruit essential oils and antimicrobial action on Penicillium digitatum and Penicillium italicum. International Journal of Food Microbiology, 43, 73-79.

[18] Chaisawadi, S., Thongbute, D., Methawiriyaslip, W., Pitak-worarat, N., Chaisawadi, A., Jaturonrasamee, K., Khemkhaw, J., \& Thnuthumchareon, W. (2003). Pre-liminary study of antimicrobial activities on medicinal herbs of Thai food ingredients. Acta Hort., 675, 111-114.

[19] Uthumporn, K., Warunya, W. (2013). Fungitoxicity of 1,2-substituted benzimidazole derivatives against Fusarium spp. The Journal of Interdisciplinary Networks, 2, 150-156.

[20] Singh, G., Maurya, S., Lampasona, M. P., \& Cantalan, C. A. N. (2007). A comparision of chemical, antioxidant and antimicrobial studies of cinnamon leaf and bark volatile oils, oleoresins and their constituents. Food and Chemical Toxicology, 45, 1650-1661.

[21] Soraluk, J. (2014). The study of benzimidazole derivative by the synthesis of citronellal. Unpublished undergraduate special problem, Maejo University, Thailand.

[22] Mariajancyrani, J., Chandramohan, G., \& Kumaravel, S. (2012). Evaluation of antimicrobial activity of some garden plant leaves against Lactobacillus Sp, Streptococcus mitis, Candida albicans and Aspergillus nige. African Journal of Basic \& Applied Sciences, 4, 139-142.

[23] Kiewwalee, M. (2014). The study of benzimidazole derivative by the synthesis of Citrus hysterix leaf. Unpublished undergraduate special problem, Maejo University, Thailand.

[24] Mariajancyrani, J., Chandramohan, G., Saravanan, \& Elayaraja, A. (2013). Isolation and antibacterial activity of terpenoid from Bougainvillea glabra choicy leaves. Asian Journal of Plant Science and Research, 3, 70-73. 
[25] Recep, K., Saban, K., \& Ahmet, C. (2007). Screening of antibacterial Activities of twenty-one oxygenated Monoterpenes. Z. Naturforsch, 62, 507-513.

[26] Karpouhtsis, I., Pardali, E., Feggou, E., Kokkini, S., Scouras, Z. G., \& Mavragani-Tsipidou, P. (1998). Insecticidal and genotoxic activities of oregano essential oils. Journal of Agricultural and Food Chemistry, 46, 1111-1115.

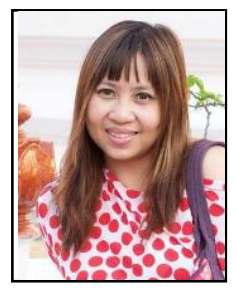

Uthumporn Kankeaw was born on December 3, 1977 in Chiang Mai of Thailand. She graduated with her B.Sc. and M.Sc. of chemistry from Chiang Mai University, and Ph.D degree of petrochemical from Chulalongkorn University in 1997. She is now a lecturer of organic chemistry and a researcher of organic chemistry in Maejo University. During lecturer time, she got research fund from National Research Council of Thailand (NRCT) to study under the topic "The synthesis of anti-fungal benzimidazole derivatives by using Desmos chinensis leaves extracted", and also got another research fund from TRF (Thailand Research Fund) for research in "The synthesis of hydroquinones antioxidants for natural rubber latex". For this research, she is working with Ratchaneeporn Rawanna, the student who studied in Maejo University moreover the research is the part of senior project.

Ratchaneeporn Rawanna was born in August 2, 1992 in Chiang Mai of Thailand, who is now studying for the B.Sc. of chemistry from Maejo University in the last semester. The field of research in organic chemistry focuses on the topic "The study of antibacteria activity of benzimidazole derivative synthesized from citronellal". 